\title{
The elephant and the blind men: making sense of PARP inhibitors in homologous recombination deficient tumor cells
}

\author{
Silvana B. De Lorenzo ${ }^{1 \dagger}$, Anand G. Patel ${ }^{1,2 \dagger}$, Rachel M. Hurley ${ }^{2}$ and Scott H. Kaufmann ${ }^{1,2 *}$ \\ Division of Oncology Research, Mayo Clinic, Rochester, MN, USA \\ ${ }^{2}$ Department of Molecular Pharmacology and Experimental Therapeutics, Mayo Clinic, Rochester, MN, USA
}

Edited by:

Christina Annunziata, National Cancer Institute, USA

\section{Reviewed by:}

Marco Barchi, University of Rome Tor

Vergata, Italy

Michael J. Metzger, Columbia

University, USA

\section{*Correspondence:}

Scott H. Kaufmann, Division of Oncology Research, Mayo Clinic, Gonda 19-212, 200 First Street, SW, Rochester, MN 55905, USA

e-mail: kaufmann.scott@mayo.edu

+ Silvana B. De Lorenzo and Anand G. Patel have contributed equally to this work.
Poly(ADP-ribose) polymerase 1 (PARP1) is an important component of the base excision repair (BER) pathway as well as a regulator of homologous recombination (HR) and nonhomologous end-joining (NHEJ). Previous studies have demonstrated that treatment of HR-deficient cells with PARP inhibitors results in stalled and collapsed replication forks. Consequently, HR-deficient cells are extremely sensitive to PARP inhibitors. Several explanations have been advanced to explain this so-called synthetic lethality between HR deficiency and PARP inhibition: (i) reduction of BER activity leading to enhanced DNA double-strand breaks, which accumulate in the absence of HR; (ii) trapping of inhibited PARP1 at sites of DNA damage, which prevents access of other repair proteins; (iii) failure to initiate HR by poly(ADP-ribose) polymer-dependent BRCA1 recruitment; and (iv) activation of the NHEJ pathway, which selectively induces error-prone repair in HR-deficient cells. Here we review evidence regarding these various explanations for the ability of PARP inhibitors to selectively kill HR-deficient cancer cells and discuss their potential implications.

Keywords: PARP inhibitor, synthetic lethality, non-homologous end joining, homologous recombination, BRCA1, BRCA2, ovarian cancer, breast cancer

\section{INTRODUCTION}

Poly(ADP-ribose) polymerase (PARP) inhibitors are currently undergoing extensive testing as potential anticancer agents (113). These drugs were initially developed as modulating agents that could enhance the cytotoxicity of DNA damaging treatments such as ionizing radiation and temozolomide $(1,12,14)$. Interest in these agents was heightened by the demonstration that $B R C A 1$ and BRCA2- (BRCA1/2-) mutant cancer cells are selectively killed by single-agent PARP inhibitor treatment $(15,16)$. Consistent with these preclinical observations, the PARP inhibitor olaparib has exhibited substantial single-agent activity in BRCA1/2-mutant breast and ovarian cancer (17-21). Nonetheless, fewer than 50\% of patients with BRCA1/2-mutant cancers respond to these drugs, raising important questions about identifying patients most likely to derive benefit from PARP inhibition $(22,23)$. With this in mind, extensive efforts have been directed at further refining the mechanism of cytotoxicity of PARP inhibitors and elucidating mechanisms of resistance.

To provide a context for discussing the selective killing of BRCA1/2-deficient cells by PARP inhibitors, we first briefly outline what is known about the PARP family of enzymes and the repair of DNA double-strand breaks. We then describe and discuss four models that have been proposed to account for the selective killing of homologous recombination (HR)-deficient cells by PARP inhibitors.

\section{PARPS: A FAMILY OF ADP-RIBOSYLTRANSFERASES}

The molecular biology and biochemistry of the PARP family of ADP-ribosyltransferases have been extensively reviewed elsewhere
(24-33) and will only briefly be summarized here. Originally described in the 1960s (34-36), PARP1 is the founding member of a family of enzymes $(37,38)$ that transfer ADP-ribose moieties from the dinucleotide $\mathrm{NAD}^{+}$to polypeptide acceptors, thereby catalyzing either mono- or poly(ADP-ribosyl)ation of polypeptide substrates $(24,39,40)$. Although 18 members of the PARP family have been identified in mammalian cells $(24,25)$, only 6 are known to synthesize poly(ADP-ribose) polymers $(1,25,41)$. Three of these family members, PARP1, PARP2, and PARP3, have been implicated in DNA repair (31). Of these, PARP1 is the most abundant (up to $10^{6}$ copies/nucleus) and has been shown to play critical roles in DNA repair, epigenetic modification of chromatin, regulation of genomic stability, modulation of cellular energy pools, the regulation of transcription, and a distinct form of cell death termed parthanatos $(25-32,42)$.

Although other PARPs might play an important role in the response to PARP inhibitors (43), existing models of PARP inhibitor-induced cytotoxicity emphasize the role of PARP1. Moreover, despite the well-established effects of PARP1 modulation on transcription (28), chromatin structure $(26,28,44)$, and energy metabolism $(1,30,33)$, current explanations for the lethality of PARP inhibition in HR-deficient cells focus solely on the role of PARP1 in DNA repair.

In response to certain types of DNA damage - particularly DNA nicks and double-strand breaks - PARP1 catalytic activity increases as much as 500 -fold $(41,45,46)$. This activation reflects a recently described conformational change that is transmitted from the DNA binding domains at the N-terminus of the PARP1 molecule through intervening domains to the catalytic domain at the 
C-terminus, resulting in altered alignment of critical residues in the active site $(41,47,48)$. Once activated, PARP1 adds poly(ADPribose) moieties to a wide range of nuclear proteins, including histones, topoisomerases, and other non-histone chromatin proteins, although PARP1 itself is the major protein that is covalently modified $(41,49)$. The resulting poly(ADP-ribose) polymers not only alter the function of the covalently modified proteins (49$52)$, but also serve as a new binding site for other nuclear proteins (32, 41, 53-55).

Through this ability to synthesize poly(ADP-ribose) polymer, which covalently or non-covalently interacts with a variety of nuclear proteins, PARP1 contributes to a number of different steps in DNA damage response pathways. In its most extensively studied role, PARP1 is essential for base excision repair (BER) (56-58), a process involving the removal of a single damaged base and subsequent restoration of DNA integrity $(59,60)$. After recruitment to the damaged DNA, PARP1 recruits the scaffolding protein $\mathrm{X}$ ray cross complementing protein 1 (XRCC1) $(57,61)$, which in turn binds to various BER proteins, bringing together a variety of components required for efficient repair of different base lesions $(59,62)$.

The involvement of PARP1 in DNA repair is not limited to XRCC1 recruitment during BER. PARP1 has also been reported to play a critical role in HR (63-65), including recruitment of MRE11 and NBS1 to DNA double-strand breaks (66), and to competitively inhibit the classical non-homologous end-joining (NHEJ) pathway by preventing Ku binding to free DNA ends (67). In addition, PARP1 plays a critical role in restarting replication forks that stall as a consequence of nucleotide depletion or collisions with bulky lesions (68-71). Any or all of these roles of PARP1 in DNA repair might be important in understanding the cellular effects of PARP inhibitors.

\section{HOMOLOGOUS RECOMBINATION}

In order to understand the models that currently describe the action of PARP inhibitors in HR-deficient cells, we also briefly review the process of HR itself. When DNA double-strand breaks form, two pathways compete to repair them (Figure 1): HR, which is a high fidelity pathway, and NHEJ, which is error-prone. According to current understanding $(60,72,73)$, the HR pathway is activated when components of the MRN (MRE11/Rad50/Nbs1) complex bind to DNA double-strand breaks. In brief, Nbs1 brings its binding partners MRE11 and Rad50 to the nucleus, where the complex binds to double strand breaks (74). This MRN complex then recruits phosphorylated CtIP, which activates the exonuclease activity of MRE11 (75-78). After activated MRE11 resects one strand of the DNA to generate relatively short $3^{\prime}$ singlestranded DNA (ssDNA) tails, two different exonucleases, ExoI and DNA2, extend the single-stranded tails to a length of several thousand basepairs by continuing the resection $(79,80)$. The resulting ssDNA is rapidly bound by the ssDNA binding protein replication protein A (RPA), which is then replaced by Rad51 to form a nucleofilament as described in greater detail below. This Rad51-ssDNA complex facilitates homology searching and invasion of the ssDNA into homologous duplex DNA sequences of its sister chromatid. Once the resected ends are annealed to complementary strands, intervening sequence is synthesized using the intact strand as a template and ligated into place (81).

A critical step in the HR pathway is the loading of Rad51 onto ssDNA. This step is the culmination of a long series of reactions (Figure 1) that are triggered in response to DNA damage (72, 82 ). Once the MRN complex binds to DNA double-strand breaks, it also recruits and activates the DNA damage-activated kinase ATM, resulting in ATM autophosphorylation followed by sequential phosphorylation and recruitment of the histone variant $\mathrm{H} 2 \mathrm{AX}$, the "mediator" (scaffold) protein MDC-1, and several other proteins, including the tumor suppressor protein BRCA1, to sites of DNA damage $(73,82)$. Partner and localizer of $\underline{B R C A} \underline{2}$ (PALB2) binds to the C-terminus of BRCA1 and $\mathrm{N}$-terminus of BRCA2, creating a bridge to recruit BRCA2 to sites of DNA damage. BRCA2 then binds phosphorylated Rad51, targeting active Rad51 to the ssDNA (83).

This entire HR process is tightly linked to cell cycle progression in multiple ways (84). First, BRCA2 and Rad51 are only expressed in S and G2 phases of the cell cycle, making HR impossible in G1 (76). Second, the cyclin-dependent kinase CDK2, which is active primarily at the G1/S transition and in S phase, catalyzes a priming phosphorylation of CtIP that is required before DNA damage can induce CtIP binding to MRN and subsequent MRE11-initiated end resection $(85,86)$. Finally, G0 and G1 cells have not replicated their DNA and, therefore, lack sister chromatids that provide homologous sequences for HR.

\section{HR DEFICIENCY DEFINES CERTAIN MALIGNANCIES}

The complex HR process can be interrupted at any of a number of steps. In particular, HR fails to occur efficiently if genes encoding components of the MRN complex, CtIP, ATM, MDC-1, H2AX, PALB2, BRCA1, BRCA2, or Rad51 are silenced or mutated at critical residues. Mutations that disable these proteins, as well as other participants in the HR process, are often found in cancers (73). In high-grade serous ovarian cancer, for example, $B R C A 1$ and $B R C A 2$ mutations are found in roughly $15 \%$ of cases, with mutations in another dozen or more HR genes found in an additional 10-15\% of cases (87-89). While some of these mutations are familial, as many as half appear to be sporadic $(89,90)$. These mutations and the resulting genomic instability are a hallmark of high-grade serous ovarian cancer (90). Likewise, mutations in BRCA1, BRCA2, $P A L B 2$, and other components with the HR pathway are common in familial and certain subtypes of sporadic breast cancer, particularly triple negative breast cancer (91-93). PTEN is deleted or silenced in over $50 \%$ of endometrial cancers and a substantial fraction of glioblastomas and prostate cancers (94-97).

Early studies found that BRCA1- or BRCA2-deficient cells are hypersensitive to PARP inhibitors $(15,16)$. In particular, cells lacking BRCA1 or BRCA2 were more susceptible to PARP inhibitor-induced apoptosis and showed more profound growth inhibition when treated as xenografts in nude mice $(15,16)$. Subsequent investigation demonstrated that cells deficient in other HR components, including NBS1, ATM, ATR, Chk1, Chk2, Rad51, Rad54, FANCD2, FANCA, PALB2, or FANCC, are also hypersensitive to PARP inhibitors (98-100). Moreover, cells lacking the lipid phosphatase PTEN were shown to be deficient in Rad51 expression $(101,102)$, also leading to PARP inhibitor sensitivity 


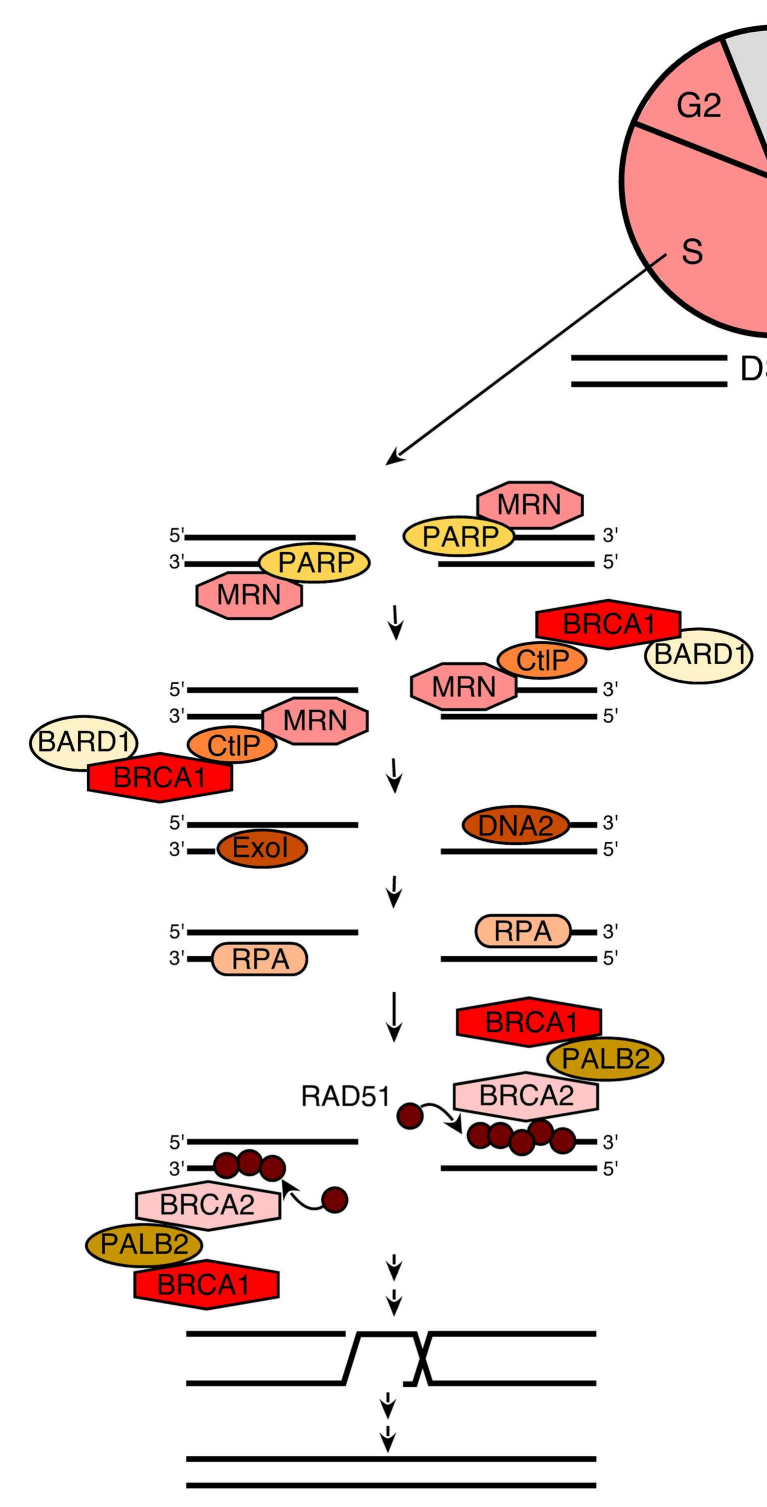

FIGURE 1 | A simplified model for NHEJ and HR. When a DNA double-strand break (DSB) occurs during G1, it is repaired via NHEJ (right). This process involves the following steps: (1) the Ku70/80 heterodimer detects and binds to the DSB; (2) Ku70/80 bound to the DSB recruits DNA-PKcs; (3) DNA-PKcs undergoes autophosphorylation, favoring the processing of DNA ends by Artemis; and (4) the XRCC4/DNA ligase IV complex ligates the processed DNA ends. Additional details regarding NHEJ can be found in refs (109-111). In contrast, when a DSB occurs during the S and G2 phases of the cell cycle, repair occurs preferentially via the HR pathway (left), which involves the following steps: (1) PARP1 binds to the DSB (48) and competes with Ku binding to DNA ends (67); (2) the MRN complex is recruited (66) to the DSB (together with CtIP and BRCA1/BARD1) and mediates the initial stages of DSB resection; (3) extensive end resection is catalyzed by EXO1 and DNA2/BLM $(79,80)$, resulting in long stretches of ssDNA; $(4)$ this SsDNA is coated by RPA; (5) the BRCA2/PALB2/BRCA1 complex facilitates replacement of RPA with Rad51 (73, 81); (6) RAD51 filaments induce strand invasion into homologous DNA sequences; (7) DNA polymerization occurs using the sister chromatid as a template; and (8) resolution of the resulting complexes produces an exact copy of the template where the DSB was generated. Additional details of the HR process can be found in Refs. $(60,72,73)$.
(102). Accordingly, the demonstration that PARP inhibitors are active, relatively non-toxic anticancer agents (17-21) led to substantial enthusiasm for developing these agents to treat a variety of neoplasms that exhibit HR deficiency.

Given the tantalizing preclinical and early clinical activity of PARP inhibitors in HR-deficient tumors, there has also been substantial interest in inducing a state of temporary HR deficiency in hopes of sensitizing cancers that lack inactivating mutations in the Fanconi anemia (FA)/HR pathway. Previous studies have demonstrated that this can be accomplished by treating cells with epidermal growth factor receptor inhibitors (103) or cyclindependent kinase inhibitors (104), which promote BRCA1 trafficking from the nucleus to the cytoplasm; phosphatidylinositol-3 kinase inhibitors, which downregulate Rad51 (105) or BRCA1 and 
BRCA2 (106); ATR inhibitors, which diminish replication stressinduced activation of cell cycle checkpoints and repair (107), or even possibly PARP inhibitors themselves (108). Whether this pharmacological inhibition of HR will sensitize cancer cells in the clinical setting as effectively as inactivating mutations in FA/HR pathway genes remains to be determined.

\section{NHEJ AS AN ALTERNATIVE MECHANISM OF DNA REPAIR}

In addition to $\mathrm{HR}$, which is a high fidelity repair process, cells also can employ the more error-prone NHEJ pathway to repair double-strand breaks. In essence, NHEJ is a process that detects free DNA ends, trims incompatible DNA, and directly ligates the double helix to restore DNA integrity (Figure 1). As reviewed elsewhere (109-111), this process involves initial binding of the $\mathrm{Ku} 70 / \mathrm{Ku} 80$ heterodimer to free DNA ends, resulting in recruitment of the large serine/threonine kinase DNA-PKcs. Once bound to the DNA terminus, DNA-PKcs phosphorylates itself as well as a number of enzymes that can process DNA ends, including the nuclease Artemis, polynucleotide kinase phosphorylase, and DNA polymerases. Finally, the DNA ends are ligated by the DNA ligase IV/XRCC4 complex. Because cells in G1 lack both the DNA substrate and much of the protein machinery required for HR, NHEJ is the major pathway used for DNA double-strand break repair during G0 and G1. Moreover, this pathway is thought to play a major role in DNA repair when HR is impaired.

Previous studies have demonstrated that the NHEJ pathway is regulated in a number of ways. First, a complex containing the large scaffolding protein 53BP1 and its binding partner Rif1 inhibits accumulation of BRCA1 and the HR regulator CtIP at sites of DNA damage, thereby facilitating NHEJ in preference to HR (112-115). Second, ATM-mediated phosphorylation modulates the activity of the NHEJ nuclease Artemis (111). Third, Ku70, Ku80, and DNA-PKcs have all been previously identified as binding partners of poly(ADP-ribose) polymer (pADPr) $(54,57)$; and more recent studies suggest that other NHEJ components such as XRCC4 and Artemis also interact with pADPr (55). Additional studies have indicated that pADPr inhibits the NHEJ pathway, providing a starting point for one of the models describing the cytotoxicity of PARP inhibitors $(15,116)$.

\section{CHOICE BETWEEN HR AND NHEJ}

Several factors determine whether a DNA double-strand break is repaired by HR or NHEJ $(117,118)$. The lack of BRCA2, Rad51, and a suitable sister chromatid as a template prevent HR during the G0 and G1 phases of the cell cycle. During S and G2 phases, on the other hand, there is a competition between HR and NHEJ. For example, Ku70 and Ku80 binding impairs double-strand break end resection, whereas resection prevents binding of the Ku70/Ku80 complex $(119,120)$. Additional studies have shown that MRN plays a primary role in removing or displacing $\mathrm{Ku}$ from DNA ends to allow resection to take place. When damage occurs during the G1 phase of the cell cycle, the 53BP1/Rif1 complex restricts CtIP recruitment and stimulation of MRE11-mediated resection as described above, thereby facilitating NHEJ (112-115). During the $S$ and G2 phases of the cell cycle, on the other hand, Rif1 is inhibited by a BRCA1-CtIP complex, allowing HR to occur. These competing interactions illustrate the complexity of processes that regulate DNA repair and provide an explanation for the observation that mechanisms involved in DNA double-strand break repair shift from NHEJ to HR during S phase (121).

\section{CURRENT EXPLANATIONS FOR THE SELECTIVE CYTOTOXICITY OF PARP INHIBITORS IN HR-DEFICIENT CELLS}

The seminal observation that PARP inhibitors selectively kill $B R C A 1 / 2$-deficient cells in preclinical models $(15,16)$ was rapidly followed by the demonstration that PARP inhibitors exhibit clinical activity against BRCA1/2-mutant tumors (17-20). At least four different explanations have been advanced to explain this so-called synthetic lethality.

\section{BER INHIBITION}

Because PARP1 plays a critical role in $\operatorname{BER}(122,123)$, initial explanations for the ability of PARP inhibitors to selectively kill HR-deficient cells focused on the interplay between BER and HR. According to this classical view [Figure 2A, see also Ref. (124, 125)], DNA damage induced by reactive oxygen species or replication errors results in DNA single-strand breaks, which ordinarily would be repaired by the BER pathway. Inhibition of PARP is postulated to cause persistence of these single-strand breaks, which are then converted to DNA double-strand breast as a consequence of interactions with transcription complexes and advancing replication forks. In HR proficient cells these DNA double-strand breaks would be repaired by HR. In the absence of BRCA1, BRCA2, or other HR components, however, impaired repair would result in persistence of these breaks and lethality. Accordingly, cells with fully active PARP1 or an intact HR pathway (BRCA1/2 wild type cells) would be expected to survive these endogenous DNA insults, whereas cells with an HR defect treated with a PARP inhibitor would not $(124,125)$.

\section{TRAPPING OF PARP1 AT SITES OF DNA DAMAGE}

An alternative model suggests that PARP1 becomes trapped on DNA in the presence of PARP inhibitors, thereby diminishing access of other repair proteins to damaged DNA. This model (Figure 2B) is based on some of the well-established characteristics of PARP1 reviewed above. In particular, PARP1 contains $\mathrm{N}$-terminal zinc fingers that recognize damaged DNA, permitting PARP1 binding to various lesions (126), and increased pADPr synthesis $(48,127,128)$. While PARP covalently modifies a wide range of substrates, most of the resulting pADPr is covalently bound to PARP1 itself (129), increasing the negative charge of the enzyme and eventually causing its dissociation from the DNA (51).

Studies performed over 20 years ago demonstrated that catalytically inactive PARP1, e.g., PARP1 lacking its substrate $\mathrm{NAD}^{+}$, inhibits DNA repair under cell-free conditions (51). Additional experiments showed that the DNA binding domain of PARP1, which is able to recognize damaged DNA but not catalyze pADPr formation, also acts as a dominant negative to enhance the cytotoxicity of certain DNA damaging treatments in intact cells $(130,131)$. PARP1 that has been catalytically inactivated by treatment with an effective small molecule inhibitor would likewise be expected to inhibit repair. This mechanism has recently been found to account for the ability of PARP inhibitors to enhance the cytotoxicity of the topoisomerase I poison topotecan (132) and the DNA methylating 


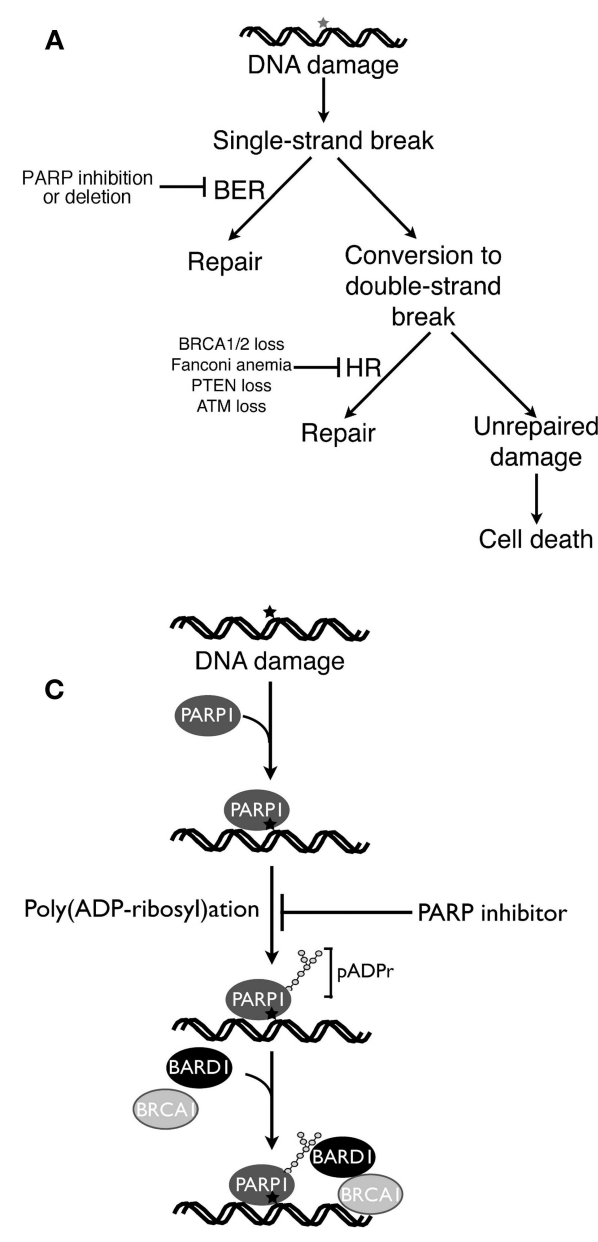

FIGURE 2 | Four current models of PARP inhibitor-induced cancer cell killing. (A), classical explanation of PARP inhibitor cytotoxicity in HR-deficient cells $(124,125)$. As described in the text, endogenous DNA damage is thought to result in DNA single-strand breaks, which ordinarily would be repaired by base excision repair (BER). If PARP inhibitors prevent BER, then persistent single-strand breaks are thought to be converted to DNA double-strand breaks, which would be repaired by HR in HR-proficient cells but remain unrepaired in HR-deficient cells. (B) Model emphasizing trapping of inhibited PARP1 at sites of DNA damage. According to this model, PARP1 binds to damaged DNA, synthesizes polymer, and then is released from the DNA so that repair enzymes can bind (51). Building on these observations, this model postulates that PARP inhibition results in failure of PARP1 to dissociate from sites of damage, leading to diminished access of other repair proteins, inhibited repair, and cell death. (C) Model emphasizing impaired recruitment
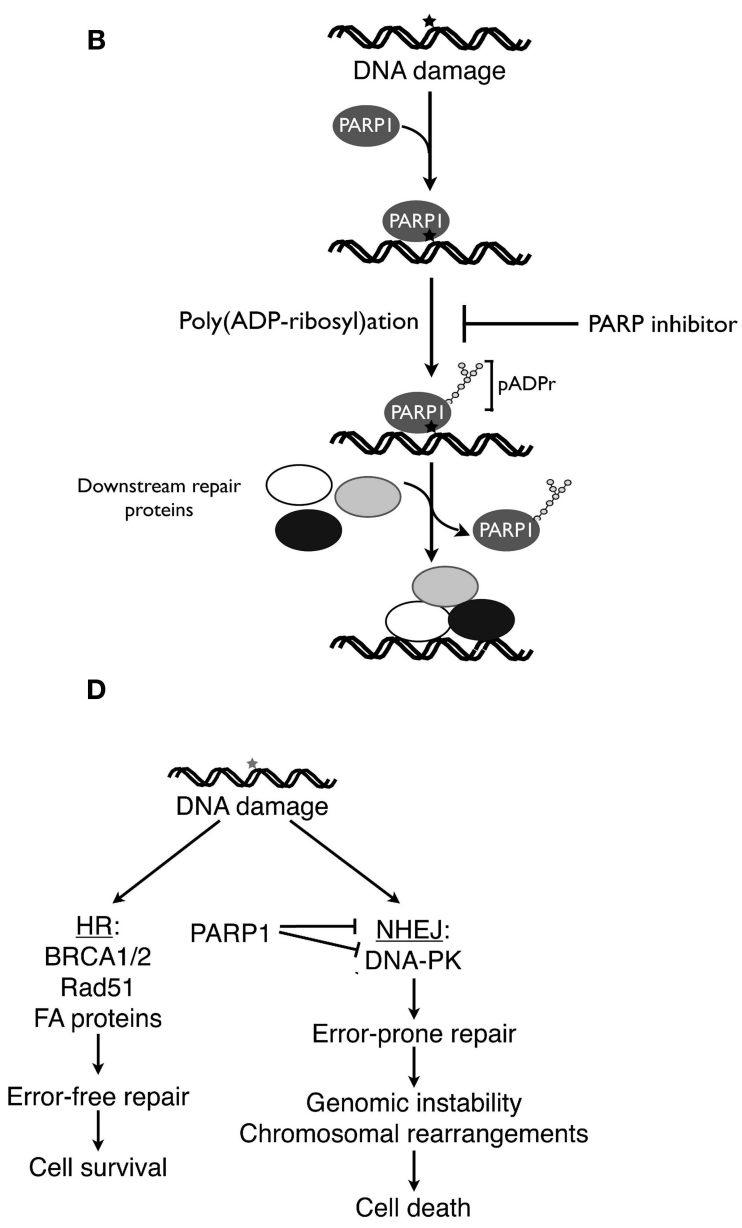

of mutated BRCA1 in the presence of PARP inhibitors. As described by Li and Yu (134), recruitment of BRCA1 to DNA double-strand breaks requires both rapid binding of the BRCA1 binding partner BARD1 to pADPr and subsequent binding of a BRCA1-containing complex to phosphorylated $\mathrm{H} 2 \mathrm{AX}$ at the break. Mutations that impair recruitment of the BRCA1-containing complex to phosphorylated $\mathrm{H} 2 \mathrm{AX}$ render BRCA1 localization to sites of damage more dependent on the BARD1-pADPr interaction and, therefore, more sensitive to PARP inhibitors. (D), model emphasizing the role of activated NHEJ in PARP inhibitor killing. When DNA double-strand breaks occur, HR preferentially repairs them. In HR-deficient cells, however, double-strand breaks are more frequently repaired by the error-prone NHEJ pathway, resulting in mutations, chromosomal rearrangements, and NHEJ-mediated cell death. PARP inhibitors accelerate this process by removing a brake on NHEJ (116). (A,D) are modified from Patel et al. (116). agent methylmethane sulfonate (MMS) (133). Extrapolating from these observations, it has been suggested that trapping of PARP1 at sites of endogenous DNA damage might account for the ability of PARP inhibitors to kill HR-deficient cells (Figure 2B).

\section{DEFECTS IN RECRUITMENT OF BRCA1 TO SITES OF DNA DAMAGE}

$\mathrm{Li}$ and $\mathrm{Yu}$ recently reported that recruitment and retention of BRCA1 at sites of DNA damage reflects two different processes, (i) an initial interaction between poly(ADP-ribose) polymer at the damage site and the BRCT domain of the BRCA1 binding partner BARD1 and (ii) subsequent slower binding of a BRCA1-containing protein complex to phosphorylated histone $\mathrm{H} 2 \mathrm{AX}$ at the damage site (134). Mutations that impair BARD1 interactions with poly(ADP-ribose) polymer, BARD1-BRCA1 complex formation, or binding of the BRCA1-containing protein complex to phosphorylated $\mathrm{H} 2 \mathrm{AX}$ all reduce survival after DNA damage. Moreover, in the presence of PARP inhibitors, the initial rapid recruitment of the BARD1-BRCA1 complex to sites of DNA damage is impaired, making the cells more dependent on phospho-H2AX-mediated BRCA1 recruitment. Conversely, when mutations in the BRCT domain of BRCA1 impair participation of BRCA1 in the complex that interacts with phospho-H2AX, recruitment of BRCA1 to 
sites of DNA damage becomes dependent on poly(ADP-ribose)mediated recruitment of BARD1 (134), providing another model to explain synthetic lethality between $B R C A 1$ mutations and PARP inhibitor treatment (Figure 2C).

\section{NHEJ ACTIVATION}

Although PARP1 clearly plays an important role in $\operatorname{BER}(14,122)$, it is important to emphasize that PARP also regulates other repair processes $(1,30,123,135)$ as described above. Earlier observations suggested that a variety of DNA repair proteins, including Ku70, $\mathrm{Ku} 80$, and DNA-PKcs, can be regulated by ADP-ribosylation (135). In particular, Ku70, Ku80, DNA-PKcs, and more recently Artemis were identified as pADPr binding proteins (53-55). Moreover, the interactions of Ku70 and Ku80 with pADPr inhibit classical NHEJ $(67,136-138)$. These observations prompted several groups to examine the potential contribution of NHEJ pathway activation to PARP inhibitor-induced killing of HR-deficient cells.

Collectively, these studies have provided several pieces of evidence suggesting an important role for NHEJ activation in PARP inhibitor-induced killing. PARP inhibitor treatment results in DNA-PKcs activation in HR-deficient cells, as manifested by DNAPKcs autophosphorylation and phosphorylation of the downstream substrate H2AX in a DNA-PK-dependent fashion (116). This PARP inhibitor-induced DNA-PKcs activation is accompanied by increased NHEJ activity as indicated by assays for repair of a plasmid that has a DNA double-strand break (116). Moreover, PARP inhibitors selectively induce chromosomal rearrangements and mutations in HR-deficient cells $(15,116)$. Importantly, this PARP inhibitor-induced increase in chromosomal rearrangements and mutations is diminished by simultaneous treatment of HRdeficient cells with a selective DNA-PK inhibitor (116). Likewise, the cytotoxicity of PARP inhibitors is diminished by manipulations that diminish NHEJ activation, including Ku80 siRNA (116), DNA-PKcs inhibition (116), or DNA-PKcs deficiency (116, 139, 140). Based on these results, a model for PARP inhibitor-induced cytotoxicity that emphasizes activation of the NHEJ pathway has been proposed (Figure 2D). In this model, some endogenous source of DNA damage results in DNA double-strand breaks. If cells are HR proficient, the HR pathway repairs this damage with high fidelity. If cells are HR deficient, however, then end resectiondependent NHEJ is activated (116) and contributes to error-prone repair that results in mutations and chromosomal rearrangements (Figure 2D).

Consistent with this model, deletion of 53BP1, which is required for NHEJ pathway activation, leads to PARP inhibitor resistance (141). Likewise, 53BP1 loss was shown to rescue the lethality of deleterious BRCA1 mutation in mouse models (142, 143), suggesting that BRCA1 deficiency kills mouse cells by activating NHEJ.

\section{THE ELEPHANT AND THE BLIND MEN}

Like the blind men examining the elephant, each of these models emphasizes a different aspect of PARP1 biology. Just as none of the blind men in the parable could provide a complete description of the elephant, we believe that the present models explain certain facets of PARP inhibitor-induced lethality but also leave some questions unanswered.

\section{The role of poly(ADP-ribose) polymers in recruitment of BRCA1 to sites of DNA damage}

The observations summarized in Figure $2 \mathrm{C}$ provide substantial new insight into the recruitment of BRCA1 to sites of DNA damage. Nonetheless, this model fails to explain PARP inhibitor sensitivity of HR-deficient cells in general. As the authors themselves point out, this model cannot explain the enhanced PARP inhibitor sensitivity of cells that totally lack BRCA1 (as opposed to expressing a BRCT domain mutant). Moreover, it is unclear how this model accounts for the synthetic lethality observed when cells lacking BRCA2, Rad51, or other downstream components of the FA/HR pathway are treated with PARP inhibitors $(15,98)$.

\section{Trapping of PARP1 at sites of DNA damage}

We are concerned that the model shown in Figure $\mathbf{2 B}$ also fails to account for critical observations regarding PARP inhibitorinduced killing. In particular, this model is a classical enzyme poisoning model, where the inhibited enzyme becomes an agent that contributes to cellular demise. This type of model, for example, accounts for the cytotoxicity of topoisomerase I poisons such as camptothecin (144). For this class of drugs, the poisoning model accounts for a number of critical observations: (i) loss of the target enzyme is not lethal $(145,146)$; and (ii) because the lethality results from the cytotoxic action of the inhibited enzyme rather than the inhibition of product production, the killing effect is observed at concentrations far below those that inhibit all activity of the enzyme (144). Importantly, this type of model accurately predicts that elevated expression of the target enzyme will increase the lethality of drugs that poison the enzyme and diminished expression of the target enzyme will decrease the lethality of the poisons (144).

Recent reports suggest that PARP inhibitors sensitize to certain DNA damaging agents by poisoning PARP1 (Figure 2B) as proposed by Lindahl and coworkers two decades ago (51). In particular, it has been reported that cells selected for resistance to the DNA methylating agent temozolomide in combination with the PARP inhibitor veliparib express markedly diminished levels of PARP1 (147). As the authors point out, this is difficult to explain if PARP inhibitors are sensitizing cells by diminishing total cellular levels of poly(ADP-ribose) polymer below a critical threshold (catalytic inhibition) but are readily understood by the poisoning model put forward in Figure 2B. Likewise, recent studies of topoisomerase I poison/PARP inhibitor combinations are also compatible with this type of PARP1 poisoning model (132). In particular, PARP1 downregulation or knockout abolishes the ability of the PARP1 inhibitor veliparib to sensitize cells to topotecan or camptothecin, establishing PARP1 as the critical target for this sensitization. Importantly, however, PARP1 knockdown or knockout does not result in cells that are hypersensitive to camptothecin or topotecan (132). Instead, Parp1 $1^{-1-}$ cells and Parp $^{+/+}$cells exhibit identical camptothecin sensitivity in the absence of PARP inhibitors (132), suggesting that PARP1 catalytic activity is not essential for camptothecin resistance. Parp1 gene deletion likewise protects chicken DT40 cells from the methylating 
agent MMS in combination with PARP inhibitors without rendering the cells hypersensitive to MMS alone (133), suggesting that PARP1 catalytic activity is also not required for MMS resistance. Consistent with a poisoning model, further experiments examining the topoisomerase I poison/PARP inhibitor combination have shown that transfection of Parp1 $1^{-1-}$ cells with catalytically inactive PARP1 or the isolated PARP1 DNA binding domain sensitizes to camptothecin just like treating Parp1 $1^{+/+}$cells with a PARP inhibitor (132). Collectively, these observations suggest that trapping of inhibited PARP1 on damaged DNA, which has previously been reported to prevent access of repair complexes (51), contributes to the cytotoxicity of certain types of drug-induced DNA lesions $(133,147,148)$ as illustrated in Figure 2B.

On the other hand, it is difficult to see how the poisoning model in Figure 2B can account for the synthetic lethality between HR deficiency and PARP inhibition. As described above, this type of model in which the inhibited enzyme is the lethal agent predicts that cells lacking PARP1 will be resistant to PARP inhibitors and cells containing elevated PARP1 levels will be hypersensitive. Contrary to this prediction, a number of groups have demonstrated that PARP1 downregulation kills BRCA1/2deficient cells $(15,16,116)$, suggesting that PARP inhibitors are killing BRCA1/2-deficient cells by diminishing the production of poly(ADP-ribose) polymer rather than trapping PARP1 at sites of DNA damage.

\section{BER inhibition}

In contrast to the preceding model, the classical model that focuses on the role of PARP1 in BER (Figure 2A) is consistent with the observation that PARP knockdown kills HR-deficient cells. It should also be acknowledged that this model provided part of the rationale for testing PARP inhibitors in BRCA2-deficient cells in the first place (16). Nonetheless, this model makes several predictions that have been difficult to verify experimentally.

First, the model predicts that DNA ss breaks will accumulate after PARP inhibition. Work by Helleday and coworkers, however, has demonstrated no induction of ss breaks by PARP inhibitors $(149,150)$. It is, of course, possible that the putative PARP inhibitor-induced ss breaks are converted to DNA doublestrand breaks so rapidly that they are not detected. Further study of this issue, perhaps with more sensitive assays for DNA ss breaks, appears to be warranted.

A second issue relates to the reported effects of XRCC1 knockdown. If ss break repair is playing a critical role in the cytotoxicity of PARP inhibitors, then the effect of downregulating other ss break repair components such as the scaffolding protein XRCC1 immediately downstream of PARP1 (151) should recapitulate the effect of PARP1 downregulation. However, XRCC1 downregulation has no impact on survival of BRCA2-mutant PEO1 ovarian cancer cells, whereas PARP1 downregulation is cytotoxic (116). Importantly, the XRCC1 knockdown was sufficient to sensitize the cells to MMS, suggesting that BER had been inhibited. These results imply that PARP1 exerts a role outside of ss break repair in HR-deficient cells (116).

Collectively, these observations call into question the suggestion that PARP inhibitors are inducing so-called synthetic lethality in the setting of HR by inhibiting ss break repair. Further testing of additional predictions of the model shown in Figure 2A is clearly needed.

\section{NHEJ activation}

As indicated above, a number of observations suggest that NHEJ plays a critical role in PARP inhibitor-induced killing $(15,116$, 139-141). The model shown in Figure 2D, which emphasizes the role of PARP in regulating NHEJ, is consistent with these observations. Nonetheless, a number of questions about this model also remain unanswered.

First, it is unclear whether all components of the NHEJ pathway contribute equally to PARP inhibitor sensitivity. Available studies only show what happens if 53BP1, Ku80, or DNA-PKcs is disabled. In view of observations that "atypical" NHEJ can occur in the absence of certain components (110), it remains to be determined whether loss of Artemis, XRCC4, ligase 4, or other NHEJ components has the same impact on PARP inhibitor sensitivity.

Second, the available data suggest that inhibiting the NHEJ pathway diminishes cytotoxicity of PARP inhibitors in HRdeficient cells. However, additional research is needed to determine how these cells survive and repair DNA double-strand breaks if HR and NHEJ are both disabled.

Third, preclinical and clinical studies have suggested that PARP inhibitors are particularly effective in tumors that have deleterious mutations in HR pathway genes such as BRCA1 and BRCA2. In contrast, tumors such as triple negative breast cancer that have $B R C A 1 / 2$ gene methylation appear to be less sensitive. It is unclear whether this reflects incomplete inhibition of the HR pathway by methylation, or whether NHEJ pathway genes might also be methylated in these tumors, leading to a repair status similar to BRCA2-mutant cells in which NHEJ components have been downregulated.

Finally, the model summarized in Figure 2D fails to specify the source of DNA damage that activates the NHEJ pathway. Given the importance of this putative damage to PARP inhibitor-induced killing, this question clearly warrants further study.

\section{Should the models be combined?}

Like the blind men in the parable, perhaps we can better understand the true nature of the elephant by merging several incomplete pictures. For example, it has been suggested (150) that inhibition of ss break repair (Figure 2A) might generate the DNA double-strand breaks (Figure 2D) that activate NHEJ and contribute to the cytotoxicity of PARP inhibitors. This would certainly be consistent with some of the known roles of PARP1 in DNA repair described above. On the other hand, the failure of PARP inhibitors to increase DNA ss breaks (149), like the failure of XRCC1 downregulation to reproduce the effects of PARP1 downregulation in BRCA2-deficient cells (116), raises concern that the hybrid model might not adequately account for the DNA damage that contributes to NHEJ-mediated killing. Given the other roles of PARP1, e.g., in restarting stalled replication forks (68-71), it is equally plausible that PARP inhibitor-induced collapse of stalled replication forks or disruption of some other PARP1-mediated process provides the DNA double-strand breaks that trigger NHEJ. Clearly, like the blind men, we require additional information to generate a coherent picture. 


\section{TRANSLATION TO THE CLINIC: WHY THE CORRECT MECHANISM MATTERS}

In contrast to chronic myelogenous leukemia, where the vast majority of patients respond to a Bcr/Abl kinase inhibitor (152), or BRAF V600E-mutant melanoma, where the response to vemurafenib is also above $50 \%(153,154)$, early studies have suggested that PARP inhibitors have only a $30-40 \%$ response rate in BRCA1/2-mutant ovarian and breast cancers (19-21). In an era of increasingly personalized cancer treatment, a less than $50 \%$ chance of responding to a supposedly tailored therapy is somewhat disconcerting (22). By understanding the mechanistic basis for the synthetic lethality between HR deficiency and PARP inhibition, it might be possible to better understand why some HR-deficient cancers respond and others do not.

The models described above make different predictions about the cancers most likely to benefit from PARP inhibitor therapy. For example, the poisoning model shown in Figure 2C predicts that HR-deficient tumors with elevated PARP1 levels should be hypersensitive to PARP inhibitors. In contrast, the models shown in Figures 2A,D, which emphasize catalytic inhibition of PARP1 as the triggering event, predict that HR-deficient tumors with lower PARP1 levels will, if all other factors are equal, be more sensitive to PARP1 inhibitors because they will require less drug to decrease poly(ADP-ribose) polymer levels below a critical threshold. The model shown in Figure 2D further predicts that HR-deficient cancers with diminished levels of NHEJ proteins will be relatively resistant to PARP inhibitors, whereas the model in Figure 2A predicts that HR-deficient cancers with diminished levels of NHEJ proteins will be more sensitive to PARP inhibitors because they are dependent on NHEJ for repair of DNA double-strand breaks in the absence of HR.

In order to understand why some HR-deficient cancers respond to PARP inhibitors and others do not, these predictions need to be

\section{REFERENCES}

1. Rouleau M, Patel A, Hendzel MJ, Kaufmann SH, Poirier GG. PARP inhibition: PARP1 and beyond. Nat Rev Cancer (2010) 10(4):293-301. doi: $10.1038 / \mathrm{nrc} 2812$

2. Telli ML, Ford JM. PARP inhibitors in breast cancer. Clin Adv Hematol Oncol (2010) 8(9):629-35.

3. Calvert H, Azzariti A. The clinical development of inhibitors of poly(ADPribose) polymerase. Ann Oncol (2011) 22(Suppl 1):i53-9. doi:10.1093/annonc/mdq667

4. Chionh F, Mitchell G, Lindeman GJ, Friedlander M, Scott CL. The role of poly adenosine diphosphate ribose polymerase inhibitors in breast and ovarian cancer: current status and future directions. Asia Pac J Clin Oncol (2011) 7(3):197-211. doi:10.1111/j.17437563.2011.01430.x

5. Plummer R. Poly(ADP-ribose) polymerase inhibition: a new direction for BRCA and

tested in the clinic. In addition, it will also be important to assess the relationship between response and more classical determinants of drug sensitivity such as levels of the target enzyme PARP1 or drug uptake and efflux.

In order for these correlative studies to proceed, it will be important for patients enrolling in PARP inhibitor trials to undergo biopsies prior to drug treatment to determine the status of DNA repair pathway genes. Whenever possible, investigators are also encouraged to obtain additional biopsies at the time of progression in order to determine the properties of cells that have resisted PARP inhibitor treatment. In this way, future studies can potentially allow identification of patients most likely to benefit from PARP inhibitor treatment.

In summary, current models describing the mechanistic basis for selective killing of HR-deficient cells by PARP inhibitors emphasize different aspects of PARP1 biology. Just as the blind men needed more information to make sense of the elephant, we need additional information in order to understand the action of these promising new agents. Given the need to improve the therapeutic outcomes for patients with HR-deficient tumors such as high-grade serous ovarian cancer, as well as the tantalizing activity of PARP inhibitors in this setting, further preclinical and clinical efforts to understand this new class of agents appear to be warranted.

\section{ACKNOWLEDGMENTS}

We gratefully acknowledge helpful discussions with Elizabeth Swisher, Clare Scott, Paul Haluska, Larry Karnitz, and Guy Poirier; insightful suggestions of the reviewers; and editorial assistance of Deb Strauss. Support for our studies has been provided by P50 CA136393, a Program Project Development Grant from the Ovarian Cancer Research Fund, T32 GM072474, and predoctoral fellowships from the Mayo Foundation for Education and Research.

Curr Pharm Des (2012) 18(25):3770-4. doi:10.2174/ 138161212802002823

11. Banerjee S, Kaye SB. New strategies in the treatment of ovarian cancer: current clinical perspectives and future potential. Clin Cancer Res (2013) 19(5):961-8. doi:10.1158/ 1078-0432.CCR-12-2243

12. Curtin NJ, Szabo C. Therapeutic applications of PARP inhibitors: anticancer therapy and beyond. Mol Aspects Med (2013). doi:10. 1016/j.mam.2013.01.006

13. Hilton JF, Hadfield MJ, Tran MT, Shapiro GI. Poly(ADP-ribose) polymerase inhibitors as cancer therapy. Front Biosci (2013) 18:1392-406. doi:10.2741/4188

14. Durkacz BW, Omidiji O, Gray DA, Shall S. (ADP-ribose) n participates in DNA excision repair. Nature (1980) 283:593-6. doi:10. 1038/283593a0

15. Farmer H, McCabe N, Lord CJ, Tutt AN, Johnson DA, Richardson $\mathrm{TB}$, et al. Targeting the DNA repair defect in
BRCA mutant cells as a therapeutic strategy. Nature (2005) 434(7035):917-21. doi:10.1038/ nature03445

16. Bryant HE, Schultz N, Thomas HD, Parker KM, Flower D, Lopez E, et al. Specific killing of BRCA2 deficient tumours with inhibitors of poly(ADP-ribose) polymerase. Nature (2005) 434(7035): 913-7. doi:10.1038/nature03443

17. Fong PC, Boss DS, Yap TA, Tutt A, Wu P, Mergui-Roelvink M, et al. Inhibition of poly(ADPribose) polymerase in tumors from BRCA mutation carriers. $N$ Engl J Med (2009) 361(2):123-34. doi:10.1056/ NEJMoa0900212

18. Fong PC, Yap TA, Boss DS, Carden CP, Mergui-Roelvink M, Gourley $\mathrm{C}$, et al. Poly(ADP)-ribose polymerase inhibition: frequent durable responses in BRCA carrier ovarian cancer correlating with platinum-free interval. J Clin Oncol (2010) 28(15):2512-9. doi: 10.1200/JCO.2009.26.9589 
19. Audeh MW, Carmichael J, Penson RT, Friedlander M, Powell B, Bell-McGuinn KM, et al. Oral poly(ADP-ribose) polymerase inhibitor olaparib in patients with BRCA1 or BRCA2 mutations and recurrent ovarian cancer: a proof-of-concept trial. Lancet (2010) 376(9737):245-51. doi:10. 1016/S0140-6736(10)60893-8

20. Tutt A, Robson M, Garber JE, Domchek SM, Audeh MW, Weitzel $\mathrm{JN}$, et al. Oral poly(ADP-ribose) polymerase inhibitor olaparib in patients with BRCA1 or BRCA2 mutations and advanced breast cancer: a proof-of-concept trial. Lancet (2010) 376(9737):235-44. doi:10.1016/S0140-6736(10) 60892-6

21. Gelmon KA, Tischkowitz M, Mackay H, Swenerton K, Robidoux A, Tonkin $\mathrm{K}$, et al. Olaparib in patients with recurrent high-grade serous or poorly differentiated ovarian carcinoma or triplenegative breast cancer: a phase 2, multicentre, open-label, nonrandomised study. Lancet Oncol (2011) 12(9):852-61. doi:10.1016/ S1470-2045(11)70214-5

22. Chan SL, Mok T. PARP inhibition in BRCA-mutated breast and ovarian cancers. Lancet (2010) 376(9737):211-3. doi:10.1016/ S0140-6736(10)61119-1

23. Balmana J, Domchek SM, Tutt A, Garber JE. Stumbling blocks on the path to personalized medicine in breast cancer: the case of PARP inhibitors for BRCA1/2associated cancers. Cancer Discov (2011) 1(1):29-34. doi:10.1158/ 2159-8274.CD-11-0048

24. Schreiber V, Dantzer F, Ame JC, de Murcia G. Poly(ADP-ribose): novel functions for an old molecule. Nat Rev Mol Cell Biol (2006) 7(7):517-28. doi:10.1038/ nrm1963

25. Hassa PO, Hottiger MO. The diverse biological roles of mammalian PARPS, a small but powerful family of poly-ADP-ribose polymerases. Front Biosci (2008) 13:3046-82. doi: 10.2741/2909

26. Quenet D, El Ramy R, Schreiber V, Dantzer F. The role of poly(ADP-ribosyl)ation in epigenetic events. Int $J$ Biochem Cell Biol (2009) 41(1):60-5. doi:10.1016/j.biocel.2008.07.023

27. Caiafa P, Guastafierro T, Zampieri M. Epigenetics: poly(ADPribosyl)ation of PARP-1 regulates genomic methylation patterns. FASEB J (2009) 23(3):672-8. doi:10.1096/fj.08-123265
28. Krishnakumar R, Kraus WL. The PARP side of the nucleus: molecular actions, physiological outcomes, and clinical targets. Mol Cell (2010) 39(1):8-24. doi:10. 1016/j.molcel.2010.06.017

29. Messner S, Hottiger MO Histone ADP-ribosylation in DNA repair, replication and transcription. Trends Cell Biol (2011) 21(9):534-42. doi:10.1016/j.tcb.2011.06.001

30. Luo X, Kraus WL. On PAR with PARP: cellular stress signaling through poly(ADPribose) and PARP-1. Genes Dev (2012) 26(5):417-32. doi:10.1101/gad.183509.111

31. Sousa FG, Matuo R, Soares DG, Escargueil AE, Henriques JA, Larsen AK, et al. PARPs and the DNA damage response. Carcinogenesis (2012) 33(8):1433-40. doi: 10.1093/carcin/bgs132

32. Gibson BA, Kraus WL. New insights into the molecular and cellular functions of poly(ADPribose) and PARPs. Nat Rev Mol Cell Biol (2012) 13(7):411-24. doi: $10.1038 / \mathrm{nrm} 3376$

33. Bai P, Canto C. The role of PARP-1 and PARP-2 enzymes in metabolic regulation and disease. Cell Metab (2012) 16(3):290-5.

34. Chambon P, Weill JD, Mandel P. Nicotinamide mononucleotide activation of new DNA-dependent polyadenylic acid synthesizing nuclear enzyme. Biochem Biophys Res Commun (1963) 11:39-43. doi: 10.1016/0006-291X(63)90024-X

35. Sugimura T, Fujimura S, Hasegawa S, Kawamura Y. Polymerization of the adenosine $5^{\prime}$-diphosphate ribose moiety of NAD by rat liver nuclear enzyme. Biochim Biophys Acta (1967) 138(2):438-41. doi:10. 1016/0005-2787(67)90507-2

36. Nishizuka Y, Ueda K, Nakazawa K, Hayaishi O. Studies on the polymer of adenosine diphosphate ribose. I. Enzymic formation from nicotinamide adenine dinuclotide in mammalian nuclei. J Biol Chem (1967) 242(13):3164-71.

37. Ame JC, Spenlehauer C, de Murcia G. The PARP superfamily. Bioessays (2004) 26(8):882-93. doi:10. 1002/bies.20085

38. Hassa PO, Haenni SS, Elser M, Hottiger MO. Nuclear ADP-ribosylation reactions in mammalian cells: where are we today and where are we going? Microbiol Mol Biol Rev (2006) 70(3):789-829. doi:10.1128/MMBR.00040-05 39. Burkle A. Physiology
and pathophysiology of poly(ADP-ribosyl)ation. Bioessays (2001) 23(9):795-806 doi:10.1002/bies.1115

40. Kim MY, Zhang T, Kraus WL. Poly(ADP-ribosyl)ation by PARP1: 'PAR-laying' NAD+ into a nuclear signal. Genes Dev (2005) 19(17):1951-67.

41. Hassler M, Ladurner AG. Towards a structural understanding of PARP1 activation and related signalling ADPribosyl-transferases. Curr Opin Struct Biol (2012) 22(6):721-9. doi:10.1016/j.sbi.2012.08.005

42. Hong SJ, Dawson TM, Dawson VL. Nuclear and mitochondrial conversations in cell death: PARP-1 and AIF signaling. Trends Pharmacol Sci (2004) 25(5):259-64. doi: 10.1016/j.tips.2004.03.005

43. Wahlberg E, Karlberg $T$, Kouznetsova E, Markova N, MacChiarulo A, Thorsell AG, et al. Family-wide chemical profiling and structural analysis of PARP and tankyrase inhibitors. Nat Biotechnol (2012) 30(3):283-8. doi:10.1038/nbt.2121

44. de Murcia G, Huletsky A, Poirier GG. Modulation of chromatin structure by poly(ADPribosyl)ation. Biochem Cell Biol (1988) 66(6):626-35. doi:10.1139/o88-072

45. Mendoza-Alvarez H, AlvarezGonzalez R. The $40 \quad \mathrm{kDa}$ carboxy-terminal domain of poly(ADP-ribose) polymerase-1 forms catalytically competent homo- and heterodimers in the absence of DNA. J Mol Biol (2004) 336(1):105-14. doi:10.1016/j.jmb.2003.11.055

46. Mendoza-Alvarez H, AlvarezGonzalez R. Poly(ADP-ribose) polymerase is a catalytic dimer and the automodification reaction is intermolecular. J Biol Chem (1993) 268(30):22575-80.

47. Langelier MF, Planck JL, Roy S, Pascal JM. Structural basis for DNA damage-dependent poly(ADP-ribosyl)ation by human PARP-1. Science (2012) 336(6082):728-32. doi:10.1126/science.1216338

48. Langelier MF, Pascal JM. PARP1 mechanism for coupling DNA damage detection to poly(ADPribose) synthesis. Curr Opin Struct Biol (2013) 23(1):134-43. doi:10. 1016/j.sbi.2013.01.003

49. Althaus FR, Richter C. ADPribosylation of proteins. Enzymology and biological significance.
Mol Biol Biochem Biophys (1987) 37:1-126.

50. Realini CA, Althaus FR. Histone shuttling by poly(ADPribosylation). J Biol Chem (1992) 267(26):18858-65.

51. Satoh MS, Lindahl T. Role of poly (ADP-ribose) formation in DNA repair. Nature (1992) 356:356-8. doi:10.1038/356356a0

52. Malanga M, Althaus FR. Poly(ADP-ribose) reactivates stalled DNA topoisomerase I and induces DNA strand break resealing. $J$ Biol Chem (2004) 279:5244-8. doi:10.1074/jbc.C300437200

53. Ahel I, Ahel D, Matsusaka T, Clark AJ, Pines J, Boulton SJ, et al. Poly(ADP-ribose)-binding zinc finger motifs in DNA repair/checkpoint proteins. Nature (2008) 451(7174):81-5. doi:10.1038/nature06420

54. Gagné J-P, Isabelle M, Lo KS, Bourassa S, Hendzel MJ, Dawson VL, et al. Proteome-wide identification of poly(ADP-ribose) binding proteins and poly(ADPribose)-associated protein complexes. Nucleic Acids Res (2008) 36(22):6959-76. doi:10.1093/nar/ gkn771

55. Gagne JP, Pic E, Isabelle M, Krietsch J, Ethier C, Paquet E, et al. Quantitative proteomics profiling of the poly(ADPribose)-related response to genotoxic stress. Nucleic Acids Res (2012) 40(16):7788-805. doi:10.1093/nar/gks486

56. de Murcia JM, Niedergang C, Trucco C, Ricoul M, Dutrillaux B, Mark M, et al. Requirement of poly(ADP-ribose) polymerase in recovery from DNA damage in mice and in cells. Proc Natl Acad Sci U S A (1997) 94(14):7303-7. doi:10.1073/pnas.94.14.7303

57. Masson M, Niedergang C, Schreiber V, Muller S, Menissierde Murcia J, de Murcia G. XRCC1 is specifically associated with poly(ADP-ribose) polymerase and negatively regulates its activity following DNA damage. Mol Cell Biol (1998) 18(6):3563-71.

58. Trucco C, Oliver FJ, de Murcia G, Menissier-de Murcia J. DNA repair defect in poly(ADPribose) polymerase-deficient cell lines. Nucleic Acids Res (1998) 26(11):2644-9. doi:10.1093/nar/ 26.11.2644

59. Horton JK, Watson M, Stefanick DF, Shaughnessy DT, Taylor JA, Wilson SH. XRCC1 and DNA polymerase beta in cellular 
protection against cytotoxic DNA single-strand breaks. Cell Res (2008) 18(1):48-63. doi:10.1038/ cr.2008.7

60. Curtin NJ. DNA repair dysregulation from cancer driver to therapeutic target. Nat Rev Cancer (2012) 12(12):801-17. doi:10. $1038 / \mathrm{nrc} 3399$

61. Okano S, Kanno S, Nakajima S, Yasui A. Cellular responses and repair of single-strand breaks introduced by UV damage endonuclease in mammalian cells. $J$ Biol Chem (2000) 275(42):32635-41. doi:10.1074/jbc.M004085200

62. Izumi T, Wiederhold LR, Roy G, Roy R, Jaiswal A, Bhakat KK, et al. Mammalian DNA base excision repair proteins: their interactions and role in repair of oxidative DNA damage. Toxicology (2003) 193(1-2):43-65. doi:10. 1016/S0300-483X(03)00289-0

63. Schultz N, Lopez E, Saleh-Gohari N, Helleday T. Poly(ADP-ribose) polymerase (PARP-1) has a controlling role in homologous recombination. Nucleic Acids Res (2003) 31(17):4959-64. doi:10.1093/nar/gkg703

64. Helleday T, Bryant HE, Schultz N. Poly(ADP-ribose) polymerase (PARP-1) in homologous recombination and as a target for cancer therapy. Cell Cycle (2005) 4(9):1176-8. doi:10.4161/cc.4.9.2031

65. Haince JF, Kozlov S, Dawson VL, Dawson TM, Hendzel MJ, Lavin MF, et al. Ataxia telangiectasia mutated (ATM) signaling network is modulated by a novel poly(ADP-ribose)-dependent pathway in the early response to DNA-damaging agents. J Biol Chem (2007) 282(22):16441-53. doi:10.1074/jbc.M608406200

66. Haince JF, McDonald D, Rodrigue A, Dery U, Masson JY, Hendzel MJ, et al. PARP1-dependent kinetics of recruitment of MRE11 and NBS1 proteins to multiple DNA damage sites. J Biol Chem (2008) 283(2):1197-208. doi:10.1074/jbc. M706734200

67. Wang $\mathrm{M}, \mathrm{Wu} \mathrm{W}$, Wu W, Rosidi B, Zhang L, Wang $\mathrm{H}$, et al. PARP1 and $\mathrm{Ku}$ compete for repair of DNA double strand breaks by distinct NHEJ pathways. Nucleic Acids Res (2006) 34(21):6170-82. doi: 10.1093/nar/gkl840

68. Yang YG, Cortes U, Patnaik S, Jasin M, Wang ZQ. Ablation of PARP-1 does not interfere with the repair of DNA double-strand breaks, but compromises the reactivation of stalled replication forks. Oncogene (2004) 23(21):3872-82. doi:10.1038/sj.onc.1207491

69. Haince JF, Rouleau M, Hendzel MJ, Masson JY, Poirier GG. Targeting poly(ADP-ribosyl)ation: a promising approach in cancer therapy. Trends Mol Med (2005) 11(10):456-63. doi:10.1016/j. molmed.2005.08.003

70. Bryant HE, Petermann E, Schultz $\mathrm{N}$, Jemth A-S, Loseva O, Issaeva $\mathrm{N}$, et al. PARP is activated at stalled forks to mediate Mrel1-dependent replication restart and recombination. EMBO J (2009) 28(17):2601-15. doi:10.1038/emboj.2009.206

71. Ying S, Hamdy FC, Helleday T. Mre11-dependent degradation of stalled DNA replication forks is prevented by BRCA2 and PARP1. Cancer Res (2012) 72(11):2814-21. doi:10.1158/ 0008-5472.CAN-11-3417

72. Ciccia A, Elledge SJ. The DNA damage response: making it safe to play with knives. $\mathrm{Mol}$ Cell (2010) 40(2):179-204. doi:10.1016/j.molcel.2010.09.019

73. Roy R, Chun J, Powell SN. BRCA1 and BRCA2: different roles in a common pathway of genome protection. Nat Rev Cancer (2012) 12(1):68-78. doi:10.1038/nrc3181

74. Stracker TH, Petrini JH. The MRE11 complex: starting from the ends. Nat Rev Mol Cell Biol (2011) 12(2):90-103. doi:10.1038/ nrm3047

75. Sartori AA, Lukas C, Coates J, Mistrik M, Fu S, Bartek J, et al. Human CtIP promotes DNA end resection. Nature (2007) 450(7169):509-14. doi:10.1038/nature06337

76. Chen L, Nievera CJ, Lee AY, Wu X. Cell cycle-dependent complex formation of BRCA1.CtIP.MRN is important for DNA double-strand break repair. J Biol Chem (2008) 283(12):7713-20. doi:10.1074/jbc. M710245200

77. Paull TT. Making the best of the loose ends: Mrel1/Rad50 complexes and Sae2 promote DNA double-strand break resection. DNA Repair (2010) 9(12):1283-91. doi:10.1016/j.dnarep.2010.09.015

78. Brosh RM Jr. DNA helicases involved in DNA repair and their roles in cancer. Nat Rev Cancer (2013) 13(8):542-58. doi:10.1038/ nrc3560

79. Huertas P. DNA resection in eukaryotes: deciding how to fix the break. Nat Struct Mol Biol
(2010) 17(1):11-6. doi:10.1038/ nsmb. 1710

80. Mimitou EP, Symington LS. DNA end resection - unraveling the tail. DNA Repair (2011) 10(3): 344-8. doi:10.1016/j.dnarep.2010. 12.004

81. Holloman WK. Unraveling the mechanism of BRCA2 in homologous recombination. Nat Struct Mol Biol (2011) 18(7):748-54.

82. Polo SE, Jackson SP. Dynamics of DNA damage response proteins at DNA breaks: a focus on protein modifications. Genes Dev (2011) 25(5):409-33. doi:10.1101/ gad.2021311

83. Carreira A, Hilario J, Amitani I, Baskin RJ, Shivji MK, Venkitaraman AR, et al. The BRC repeats of BRCA2 modulate the DNAbinding selectivity of RAD51. Cell (2009) 136(6):1032-43. doi: 10.1016/j.cell.2009.02.019

84. Trovesi C, Manfrini N, Falcettoni M, Longhese MP. Regulation of the DNA damage response by cyclindependent kinases. J Mol Biol (2013). doi:10.1016/j.jmb.2013.04. 013

85. Peterson SE, Li Y, Wu-Baer F, Chait BT, Baer R, Yan H, et al. Activation of DSB processing requires phosphorylation of CtIP by ATR. $\mathrm{Mo}$ Cell (2013) 49(4):657-67. doi:10. 1016/j.molcel.2012.11.020

86. Wang $H$, Shi LZ, Wong CC, Han X, Hwang PY, Truong LN, et al. The interaction of CtIP and Nbsl connects CDK and ATM to regulate HR-mediated double-strand break repair. PLoS Genet (2013) 9(2):e1003277. doi 10.1371/journal.pgen.1003277

87. Walsh T, Casadei S, Lee MK, Pennil CC, Nord AS, Thornton AM, et al. Mutations in 12 genes for inherited ovarian, fallopian tube, and peritoneal carcinoma identified by massively parallel sequencing. Proc Natl Acad Sci US A (2011) 108(44):18032-7. doi:10. 1073/pnas. 1115052108

88. Pennington KP, Swisher EM. Hereditary ovarian cancer: beyond the usual suspects. Gynecol Oncol (2012) 124(2):347-53. doi:10.1016/j.ygyno.2011.12.415

89. Berns EM, Bowtell DD. The changing view of high-grade serous ovarian cancer. Cancer Res (2012) 72(11):2701-4. doi:10.1158/00085472.CAN-11-3911

90. Cancer Genome Atlas Research Network. Integrated genomic analyses of ovarian carcinoma. Nature (2011) 474(7353):609-15. doi:10.1038/nature10166
91. Turner N, Tutt A, Ashworth A. Hallmarks of "BRCAness" in sporadic cancers. Nat Rev Cancer (2004) 4:814-9. doi:10.1038/ nrc1457

92. Metzger-Filho O, Tutt A, de Azambuja E, Saini KS, Viale G, Loi S, et al. Dissecting the heterogeneity of triple-negative breast cancer. J Clin Oncol (2012) 30(15): 1879-87. doi:10.1200/JCO.2011. 38.2010

93. Crown J, O'Shaughnessy J, Gullo G. Emerging targeted therapies in triple-negative breast cancer. Ann Oncol (2012) 23(Suppl 6):vi56-65. doi:10.1093/annonc/mds196

94. Merritt MA, Cramer DW. Molecular pathogenesis of endometrial and ovarian cancer. Cancer Biomark (2010) 9(1-6):287-305. doi: 10.3233/CBM-2011-0167

95. Hollander MC, Blumenthal GM, Dennis PA. PTEN loss in the continuum of common cancers, rare syndromes and mouse models. Nat Rev Cancer (2011) 11(4):289-301. doi:10.1038/nrc3037

96. McCubrey JA, Steelman LS, Kempf CR, Chappell WH, Abrams SL, Stivala F, et al. Therapeutic resistance resulting from mutations in Raf/MEK/ERK and PI3K/PTEN/Akt/mTOR signaling pathways. J Cell Physiol (2011) 226(11):2762-81. doi:10.1002/jcp.22647

97. Song MS, Salmena L, Pandolfi PP. The functions and regulation of the PTEN tumour suppressor. Nat Rev Mol Cell Biol (2012) 13(5):283-96. doi:10.1038/ nrm3330

98. McCabe N, Turner NC, Lord CJ, Kluzek K, Bialkowska A, Swift S, et al. Deficiency in the repair of DNA damage by homologous recombination and sensitivity to poly(ADP-ribose) polymerase inhibition. Cancer Res (2006) 66(16):8109-15. doi:10. 1158/0008-5472.CAN-06-0140

99. Williamson CT, Muzik H, Turhan AG, Zamo A, O’Connor MJ, Bebb DG, et al. ATM deficiency sensitizes mantle cell lymphoma cells to poly(ADP-ribose) polymerase1 inhibitors. Mol Cancer Ther (2010) 9(2):347-57. doi:10.1158/ 1535-7163.MCT-09-0872

100. Weston VJ, Oldreive CE, Skowronska A, Oscier DG, Pratt G, Dyer $\mathrm{MJ}$, et al. The PARP inhibitor olaparib induces significant killing of ATM-deficient lymphoid tumor cells in vitro and in vivo. Blood (2010) 116(22):4578-87. doi:10. 1182/blood-2010-01-265769 
101. Shen WH, Balajee AS, Wang $\mathrm{J}$, Wu $\mathrm{H}$, Eng C, Pandolfi $\mathrm{PP}$, et al. Essential role for nuclear PTEN in maintaining chromosomal integrity. Cell (2007) 128(1):157-70. doi:10.1016/j.cell.2006.11.042

102. Mendes-Pereira AM, Martin SA, Brough R, McCarthy A, Taylor JR, Kim JS, et al. Synthetic lethal targeting of PTEN mutant cells with PARP inhibitors. EMBO Mol Med (2009) 1(6-7):315-22. doi:10.1002/ emmm.200900041

103. Nowsheen S, Cooper T, Stanley JA, Yang ES. Synthetic lethal interactions between EGFR and PARP inhibition in human triple negative breast cancer cells. PLoS One (2012) 7(10):e46614. doi:10.1371/ journal.pone.0046614

104. Johnson N, Li YC, Walton ZE, Cheng KA, Li D, Rodig SJ, et al. Compromised CDK1 activity sensitizes BRCA-proficient cancers to PARP inhibition. Nat Med (2011) 17(7):875-82. doi:10.1038/ nm.2377

105. Juvekar A, Burga LN, Hu H, Lunsford EP, Ibrahim YH, Balmana J, et al. Combining a PI3K inhibitor with a PARP inhibitor provides an effective therapy for BRCA1-related breast cancer. Cancer Discov (2012) 2(11):1048-63. doi:10.1158/21598290.CD-11-0336

106. Ibrahim YH, Garcia-Garcia C, Serra V, He L, Torres-Lockhart $\mathrm{K}$, Prat A, et al. PI3K inhibition impairs BRCA1/2 expression and sensitizes BRCA-proficient triplenegative breast cancer to PARP inhibition. Cancer Discov (2012) 2(11):1036-47. doi:10.1158/21598290.CD-11-0348

107. Huntoon CJ, Flatten KS, Wahner Hendrickson AE, Huehls AM, Sutor SL, Kaufmann SH, et al. ATR inhibition broadly sensitizes ovarian cancer cells to chemotherapy independent of BRCA status. Cancer Res (2013) 73(12):3683-91. doi:10.1158/0008-5472.CAN-130110

108. Hegan DC, Lu Y, Stachelek GC, Crosby ME, Bindra RS, Glazer PM. Inhibition of poly(ADP-ribose) polymerase down-regulates BRCA1 and RAD51 in a pathway mediated by E2F4 and p130. Proc Natl Acad Sci U $S \quad A \quad(2010) \quad$ 107(5):2201-6. doi:10.1073/pnas.0904783107

109. Dobbs TA, Tainer JA, Lees-Miller SP. A structural model for regulation of NHEJ by DNA-PKcs autophosphorylation. DNA Repair (2010) 9(12):1307-14 doi:10.1016/j.dnarep.2010.09.019

110. Lieber MR. The mechanism of double-strand DNA break repair by the nonhomologous DNA end-joining pathway. Annu Rev Biochem (2010) 79:181-211. doi:10.1146/annurev.biochem. 052308.093131

111. Weterings E, Chen DJ. The endless tale of nonhomologous end-joining. Cell Res (2008) 18(1):114-24. doi:10.1038/cr.2008.3

112. Zimmermann M, Lottersberger $F$, Buonomo SB, Sfeir A, de Lange T. 53BP1 regulates DSB repair using Rif1 to control $5^{\prime}$ end resection. Science (2013) 339(6120):700-4. doi:10.1126/science.1231573

113. Di Virgilio M, Callen E, Yamane A, Zhang W, Jankovic M, Gitlin $\mathrm{AD}$, et al. Rif1 prevents resection of DNA breaks and promotes immunoglobulin class switching. Science (2013) 339(6120):711-5. doi:10.1126/science.1230624

114. Chapman JR, Barral P, Vannier JB, Borel V, Steger M, TomasLoba A, et al. RIF1 is essential for 53BP1-dependent nonhomologous end joining and suppression of DNA double-strand break resection. Mol Cell (2013) 49(5):858-71. doi:10.1016/j. molcel.2013.01.002

115. Escribano-Diaz C, Orthwein A, Fradet-Turcotte A, Xing M, Young JT, Tkac J, et al. A cell cycle-dependent regulatory circuit composed of 53BP1RIF1 and BRCA1-CtIP controls DNA repair pathway choice. Mol Cell (2013) 49(5):872-83. doi:10.1016/j.molcel.2013.01.001

116. Patel A, Sarkaria J, Kaufmann SH. Nonhomologous endjoining drives PARP inhibitor synthetic lethality in homologous recombination-deficient cells. Proc Natl Acad Sci U $S$ A (2011) 108:3406-11. doi:10.1073/pnas.1013715108

117. Symington LS, Gautier J. Doublestrand break end resection and repair pathway choice. Annu Rev Genet (2011) 45:247-71. doi:10.1146/annurev-genet110410-132435

118. Chapman JR, Taylor MR, Boulton SJ. Playing the end game: DNA double-strand break repair pathway choice. Mol Cell (2012) 47(4):497-510. doi:10.1016/j.molcel.2012.07.029

119. Langerak P, Mejia-Ramirez E, Limbo O, Russell P. Release of $\mathrm{Ku}$ and MRN from DNA ends by Mrell nuclease activity and Ctpl is required for homologous recombination repair of double-strand breaks. PLoS Genet (2011) 7(9):e1002271. doi: 10.1371/journal.pgen.1002271

120. Sun J, Lee KJ, Davis AJ, Chen DJ. Human Ku70/80 protein blocks exonuclease 1-mediated DNA resection in the presence of human Mrell or Mre11/Rad50 protein complex. Biol Chem (2012) 287(7):4936-45. doi:10.1074/jbc.M111.306167

121. Karanam K, Kafri R, Loewer A, Lahav G. Quantitative live cell imaging reveals a gradual shift between DNA repair mechanisms and a maximal use of $\mathrm{HR}$ in mid S phase. Mol Cell (2012) 47(2):320-9. doi:10.1016/j.molcel. 2012.05.052

122. Dantzer F, Schreiber V, Niedergang C, Trucco C, Flatter E, De La Rubia $\mathrm{G}$, et al. Involvement of poly(ADP-ribose) polymerase in base excision repair. Biochimie (1999) 81(1-2):69-75. doi:10. 1016/S0300-9084(99)80040-6

123. De Vos M, Schreiber V, Dantzer F. The diverse roles and clinical relevance of PARPs in DNA damage repair: current state of the art. Biochem Pharmacol (2012) 84(2):137-46. doi:10.1016/j.bcp. 2012.03.018

124. Iglehart JD, Silver DP. Synthetic lethality - a new direction in cancer-drug development. $N$ Engl J Med (2009) 361(2):189-91. doi: 10.1056/NEJMe0903044

125. Yap TA, Sandhu SK, Carden CP, de Bono JS. Poly(ADP-ribose) polymerase (PARP) inhibitors: exploiting a synthetic lethal strategy in the clinic. CA Cancer J Clin (2011) 61(1):31-49. doi:10.3322/ caac. 20095

126. de Murcia G, Menissier de Murcia J. Poly(ADP-ribose) polymerase: a molecular nick-sensor. Trends Biochem Sci (1994) 19(4):172-6.

127. Juarez-Salinas H, Sims JL, Jacobson MK. Poly(ADP-ribose) levels in carcinogen-treated cells. Nature (1979) 282:740-1. doi:10. 1038/282740a0

128. Benjamin RC, Gill DM. ADPribosylation in mammalian cell ghosts. Dependence of poly(ADPribose) synthesis on strand breakage in DNA. J Biol Chem (1980) 255(21):10493-501.

129. D'Amours D, Desnoyers S, D'Silva I, Poirier GG. Poly(ADP-ribosyl)ation reactions in the regulation of nuclear functions. Biochem $J \quad$ (1999) 342(Pt 2):249-68. doi:10.1042/0264-6021:3420249

130. Kupper JH, deMurcia G, Bürkle A. Inhibition of Poly(ADP-ribosyl)ation by overexpressing the poly(ADP-ribose) polymerase DNA-binding domain in mammalian cells. $J$ Biol Chem (1990) 265:18721-4.

131. Molinete M, Vermeulen W, Burkle A, Menissier-de Murcia J, Kupper $\mathrm{JH}$, Hoeijmakers $\mathrm{JH}$, et al. Overproduction of the poly(ADPRibose) polymerase DNA-binding domain blocks alkylation-induced DNA repair synthesis in mammalian cells. EMBO J (1993) 12:2109-17.

132. Patel AG, Flatten KS, Schneider PA, Dai NT, McDonald JS, Poirier GG, et al. Enhanced killing of cancer cells by poly(ADP-ribose) polymerase inhibitors and topoisomerase inhibitors reflects poisoning of both enzymes. J Biol Chem (2012) 287:4198-210. doi: 10.1074/jbc.M111.296475

133. Murai J, Huang SY, Das BB, Renaud A, Zhang Y, Doroshow JH, et al. Trapping of PARP1 and PARP2 by clinical PARP inhibitors. Cancer Res (2012) 72(21):5588-99. doi:10. 1158/0008-5472.CAN-12-2753

134. Li M, Yu X. Function of BRCA1 in the DNA damage response is mediated by ADP-ribosylation. Cancer Cell (2013) 23(5):693-704. doi:10. 1016/j.ccr.2013.03.025

135. Miwa M, Masutani M. PolyADPribosylation and cancer. Cancer Sci (2007) 98(10):1528-35. doi:10.1111/j.1349-7006.2007. 00567.x

136. Li B, Navarro S, Kasahara N, Comai L. Identification and biochemical characterization of a Werner's syndrome protein complex with Ku70/80 and poly(ADPribose) polymerase-1. J Biol Chem (2004) 279(14):13659-67. doi:10. 1074/jbc.M311606200

137. Hochegger H, Dejsuphong D, Fukushima T, Morrison C, Sonoda E, Schreiber V, et al. Parp-1 protects homologous recombination from interference by $\mathrm{Ku}$ and Ligase IV in vertebrate cells. $E M B O$ $J$ (2006) 25(6):1305-14. doi:10. 1038/si.emboj.7601015

138. Paddock MN, Bauman AT, Higdon R, Kolker E, Takeda S, Scharenberg AM. Competition between PARP1 and Ku70 control the decision between high-fidelity and mutagenic DNA repair. DNA Repair (2011) 10(3):338-43. doi:10.1016/ j.dnarep.2010.12.005 
139. Murai J, Yang K, Dejsuphong D, Hirota K, Takeda S, D'Andrea AD. The USP1/UAF1 complex promotes double-strand break repair through homologous recombination. Mol Cell Biol (2011) 31(12):2462-9. doi:10.1128/MCB. 05058- 11

140. Williamson CT, Kubota E, Hamill JD, Klimowicz A, Ye R, Muzik $H$, et al. Enhanced cytotoxicity of PARP inhibition in mantle cell lymphoma harbouring mutations in both ATM and p53. EMBO Mol Med (2012) 4(6):515-27. doi:10. 1002/emmm.201200229

141. Bunting SF, Callen E, Wong N, Chen HT, Polato F, Gunn A, et al. 53BP1 inhibits homologous recombination in Brcal-deficient cells by blocking resection of DNA breaks. Cell (2010) 141(2): 243-54. doi:10.1016/j.cell.2010.03. 012

142. Cao L, Xu X, Bunting SF, Liu J, Wang RH, Cao LL, et al. A selective requirement for $53 \mathrm{BP} 1$ in the biological response to genomic instability induced by Brcal deficiency. Mol Cell (2009) 35(4):534-41. doi:10.1016/j. molcel.2009.06.037

143. Bouwman P, Aly A, Escandell JM, Pieterse M, Bartkova J, van der Gulden H, et al. 53BP1 loss rescues BRCAl deficiency and is associated with triple-negative and BRCAmutated breast cancers. Nat Struct
Mol Biol (2010) 17(6):688-95. doi: $10.1038 / \mathrm{nsmb} .1831$

144. Liu LF. DNA topoisomerase poisons as antitumor drugs. Annu Rev Biochem (1989) 58:351-75. doi:10.1146/annurev. bi.58.070189.002031

145. Eng WK, Faucette L, Johnson RK, Sternglanz R. Evidence that DNA topoisomerase I is necessary for the cytotoxic effects of camptothecin. Mol Pharmacol (1988) 34(6):755-60.

146. Eng WK, McCabe FL, Tan KB, Mattern MR, Hofmann GA, Woessner RD, et al. Development of a stable camptothecin-resistant subline of P388 leukemia with reduced topoisomerase I content. Mol Pharmacol (1990) 38(4):471-80.

147. Liu X, Han EK, Anderson M, Shi Y, Semizarov D, Wang G, et al. Acquired resistance to combination treatment with temozolomide and ABT- 888 is mediated by both base excision repair and homologous recombination DNA repair pathways. Mol Cancer Res (2009) 7(10):1686-92. doi:10.1158/15417786.MCR-09-0299

148. Patel AG, De Lorenzo SB, Flatten KS, Poirier GG, Kaufmann SH. Failure of iniparib to inhibit poly(ADP-ribose) polymerase in vitro. Clin Cancer Res (2012) 18(6):1655-62. doi:10.1158/10780432.CCR-11-2890
149. Gottipati P, Vischioni B, Schultz N, Solomons J, Bryant $\mathrm{HE}$, Djureinovic $\mathrm{T}$, et al. Poly(ADP-ribose) polymerase is hyperactivated in homologous recombination-defective cells. Cancer Res (2010) 70(13):5389-98. doi:10.1158/0008-5472.CAN-094716

150. Helleday T. The underlying mechanism for the PARP and BRCA synthetic lethality: clearing up the misunderstandings. Mol Onco (2011) 5(4):387-93. doi:10.1016/j. molonc.2011.07.001

151. Caldecott KW. XRCC1 and DNA strand break repair. DNA Repair (2003) 2(9):955-69. doi:10.1016/ S1568-7864(03)00118-6

152. Druker BJ, Sawyers CL, Kantarjian H, Resta DJ, Reese SF, Ford JM, et al. Activity of a specific inhibitor of the BCR-ABL tyrosine kinase in the blast crisis of chronic myeloid leukemia and acute lymphoblastic leukemia with the Philadelphia chromosome. $N$ Engl J Med (2001) 344:1038-42. doi:10.1056/ NEJM200104053441402

153. Chapman PB, Hauschild A, Robert C, Haanen JB, Ascierto P, Larkin $\mathrm{J}$, et al. Improved survival with vemurafenib in melanoma with BRAF V600E mutation. $N$ Engl J Med (2011) 364(26):2507-16. doi: 10.1056/NEJMoa1103782

154. Sosman JA, Kim KB, Schuchter L, Gonzalez R, Pavlick AC, Weber
JS, et al. Survival in BRAF V600-mutant advanced melanoma treated with vemurafenib. $N$ Engl J Med (2012) 366(8):707-14. doi: 10.1056/NEJMoa1112302

Conflict of Interest Statement: The authors declare that the research was conducted in the absence of any commercial or financial relationships that could be construed as a potential conflict of interest.

Received: 24 June 2013; accepted: 21 August 2013; published online: 11 September 2013.

Citation: De Lorenzo SB, Patel AG, Hurley RM and Kaufmann SH (2013) The elephant and the blind men: making sense of PARP inhibitors in homologous recombination deficient tumor cells. Front. Oncol. 3:228. doi: 10.3389/fonc. 2013.00228

This article was submitted to Cancer Molecular Targets and Therapeutics, a section of the journal Frontiers in Oncology. Copyright (C) 2013 De Lorenzo, Patel, Hurley and Kaufmann. This is an openaccess article distributed under the terms of the Creative Commons Attribution License (CC BY). The use, distribution or reproduction in other forums is permitted, provided the original author(s) or licensor are credited and that the original publication in this journal is cited, in accordance with accepted academic practice. No use, distribution or reproduction is permitted which does not comply with these terms. 